\title{
MEDIA PEMBELAJARAN BAHASA INGGRIS DASAR MENGGUNAKAN MACROMEDIA FLASH 8 di TK KARTIKA 1.50 KECAMATAN SAIL KOTA PEKANBARU
}

\author{
Yuda Irawan ${ }^{1}$, Herianto $^{2}$, Refni Wahyuni ${ }^{3}$ \\ 1,2,3 STMIK Hang Tuah Pekanbaru \\ 1,2,3 Jl. Mustafa Sari No 5 Tangkerang Selatan, Pekanbaru, 28288 \\ e-mail: yudairawan89@gmail.com ${ }^{1}$,herianto.sy@gmail.com², refni.abid@gmail.com ${ }^{3}$
}

\begin{abstract}
ABSTRAK
Penelitian ini membahas tentang perancangan dan pembuatan Aplikasi Multimedia Pembelajaran Bahasa Inggris Dasar Berbasis Aplikasi Macromedia Flash 8 di TK Kartika 150 Kecamatan sail kota penyampaian materi pembelajaran bahasa inggris di tk kartika kecamatan sail kota pekanabru masih terkesan monoton. Dalam kegiatan belajar mengajar guru hanya mengandalkan buku, metode lisan dan guru tidak menggunakan media pendukung pembelajaran efektif dan kurang memperdayakan potensi siswa di tk. Dengan memanfaatkan perkembangan teknologi yaitu melalui PC/Laptop berbasis multimedia. PembuatanAplikasi Multimedia Bahasa inggris dasar untuk anak tk ini dengan menggunakan software berbasis macromedia flash 8. Pengembangan aplikasi ini menggunakan metode waterfall yang dimulai dari analisa kebutuhan sampai penerapan dan pemeliharaan sistem. Aplikasi ini menampilkan informasi tentang belajar bahasa inggris dasar yang berfokus pada materi pembelajaran mengenai materi nama sayuran, materi anggota tubuh, materi hewan, materi benda, dan warna. Aplikasi ini disertai dengan adanya game.Berdasarkan pada hasil uji coba, aplikasi ini dapat berjalan dengan baik pada perangkat berbasis multimedia dengan versi macromedia flash 8. Aplikasi multimedia ini meliputi pengenalan nama hewan, warna, tubuh, sayuran, benda dan permainan, sehingga aplikasi dapat menembah daya tarik penyampaian materi kepada siswa. Media pembelajaran interaktif ini akan membuat suasana belajar yang menyenangkan, menarik, komunikatif serta mudah dipahami murid.
\end{abstract}

Kata Kunci : Aplikasi, Multimedia, Macromedia Flash, Tk Kartika, Bahasa inggris.

\begin{abstract}
This study discusses the design and manufacture of Multimedia Applications for Basic English Learning Based on Macromedia Flash 8 Applications in TK Kartika 150 District of Sail City Submission of English learning materials in TK Kartika Subdistrict of Sail, the city of Pekanabru still seems monotonous. In teaching and learning activities teachers only rely on books, oral methods and teachers do not use media to support effective learning and do not empower students' potential in kindergarten. By utilizing technological developments, namely through multimedia-based PCs / Laptops. Making Multimedia Applications Basic English for this kindergarten child using Macromedia Flash-based software 8. Development of this application uses the waterfall method that starts from the needs analysis to the implementation and maintenance of the system. This application displays information about learning basic English that focuses on learning materials about the material names of vegetables, material for limbs, animal material, material objects, and colors. This application is accompanied by a game. Based on trial results, this application can run well on multimedia-based devices with Macromedia Flash version 8. This multimedia application includes the introduction of animal names, colors, bodies, vegetables, objects and games, so that applications can show the attraction of delivering material to students. This interactive learning media will make the learning atmosphere fun, interesting, communicative and easy for students to understand.
\end{abstract}

Keywords: Applications, Multimedia, Macromedia Flash, Tk Kartika, English. 
IN F ORMA TIK

Jurnal Informatika, Manajemen dan Komputer, Vol. 11, No. 2, Desember 2019

eISSN : 2580-3042

pISSN : 1979-0694

\section{PENDAHULUAN}

Teknologi merupakan salah satu sarana yang semakin berkembang pesat di pasaran saat ini. Teknologi dapat memberikan kemudahan bagi kehidupan masyarakat dalam berbagai hal, sehingga menjadi lebih efektif dan efesien. Perkembangan teknologi khususnya teknologi komputer berdampak pula pada perkembangan pendidikan terutama dalam hal kontens ataupun media pendukung. Pembelajaran dengan menggunakan teknologi informasi melalui media elektronik berbasis multimedia membantu menumbuhkan minat belajar secara mandiri dan mampu memgembangkan kreatifitas dan pemahaman anak didik dalam belajar. Hal ini harus mulai dikenalkan jenjang pendidikan sehingga potensi anak dapat digali sejak dini. Proses belajar mengajar yang komunikatif, efektif dan efisien mutlak dibutuhkan untuk mencapai tujuan pendidikan yang ideal, yakni menghasilkan siswa-siswi yang memahami konsep pelajaran yang disampaikan dan kegunaanya pada kehidupan sehari-hari.

Penyampaian materi pembelajaran bahasa inggris di TK Kartika Kecamatan Sail Pekanbaru saat ini masih terkesan monoton. Dalam kegiatan belajar mengajar guru hanya mengandalkan buku, metode lisan dan guru tidak menggunakan media pendukung selain buku. Metode pembelajaran seperti ini kurang memenuhi prinsip-prinsip pembelajaran yang efektif dan kurang memberdayakan pontesi siswa di TK kartika 1.50 Kecamatan Sail Kota Pekanbaru.

Seiring dengan berkembangnya teknologi informasi, saat ini sudah banyak device yang diciptakan untuk mempermudah dalam mengakses informasi dan membuat aplikasi berbasis multimedia, salah satunya yaitu program Macromedia Flash 8 untuk memberikan solusi permasalahan diatas. Macromedia Flash 8 dapat menghasilkan file animasi dengan ukuran file yang kecil dengan kualitas yang baik dan kebutuhan hadware yang tidak tinggi. Macromedia flash 8 tidak hanya digunakan untuk membuat animasi melainkan juga digunakan untuk membuat menu interaktif dan membuat presentasi software. Oleh karena itu akan dibuat suatu aplikasi pembelajaran interaktif menggunakan Macromedia Flash yang menggabungkan konsep pembelajaran teknologi audiovisual.

Pada penyusunan penelitian ini membuat aplikasi pembelajaran Bahasa Inggris di TK Kartika 1.50 Kecamatan Sail Kota Pekanabaru menggunakan macromedia flash 8. Media pembelajaran bahasa inggris berbasis multimedia ini dianggap bisa berdampak positif terhadap pemahaman materi yang disampaikan guru serta dapat menambah daya tarik minat belajar pada pembelajaran bahasa inggris dan juga untuk memaksimalkan penyampaian materi kepada siswa. Media pembelajaran interaktif ini akan membuat suasana belajar yang menyenangkan, menarik, komunikatif serta mudah di pahami murid.

Untuk penelitian selanjutnya diharapkan mengembangkan sistem pendukung keputusan untuk menetapkan penerima beasiswa di TK tersebut agar penerima beasiswa tersebut tepat sasaran dan dilakukan secara otomatis menggunakan sistem (Yuda Irawan, 2018).

\section{A. Aplikasi}

Aplikasi (application software) adalah perangkat lunak yang dikembangkan untuk menyelesaikan masalah-masalah tertentu, yakni dapat mengerjakan tugas tertentu. Perangkat lunak ini antara lain perangkat lunak produktivitas dan perangkat lunak khusus (Yakub, 20:96).

\section{B. Pembelajaran Konsep Dasar}

Media pembelajaran memegang peranan yang penting dalam proses pembelajaran. Penggunaan media pendidikan, dapat pendidikan, dapat membantu guru dalam menyampaikan materi pelajaran. Keberhasilan pembelajaran sangat ditentukan oleh dua komponen utama yaitu metode mengajar dan media pembelajaran. Kedua komponen ini saling berkaitan dan tidak bisa dipisahkan. Penggunaan dan pemilihan salah satu metode mengajar tertentu mempunyai konsekuensi pada penggunaan jenis media pembelajaran yang sesuai. Fungsi media dalam proses belajar mengajar yaitu untuk meningkatkan rangsangan peserta didik dalam kegiatan belajar. Ali, M (2005) mengatakan bahwa penggunaan media pembelajaran berbantuan komputer mempunyai pengaruh yang signifikan terhadap daya tarik siswa untuk mempelajari kompetensi yang diajarkan.Penggunaan media pembelajaran dapat menghemat waktu persiapan mengajar, meningkatkan motivasi belajar siswa, dan mengurangi kesalahpahaman siswa terhadap penjelasan yang diberikan guru (Ali, 2009).

Menurut Abdul Wahab Rosyidi (2009:26), media pembelajaran adalah semua bahan dan alat fisik yang mungkin digunakan untuk menyampaikan isi materi. Dengan demikian 
IN F ORMA TIK

Jurnal Informatika, Manajemen dan Komputer, Vol. 11, No. 2, Desember 2019

eISSN : 2580-3042

pISSN : 1979-0694

ketepatan dan tingkat representasi sebuah media terhadap pesan yang akan disampaikan dapat turut menentukan keberhasilan proses pembelajaran.

\section{Media audio visual}

Media audio visual adalah media kom binasi antara auto dan visual yang diciptakan sendiri seperti slide yang dikombinasikan dengan kaset audio" Wingkel (2009:321). Menurut wina sanjaya (2010:172) "media audio visual adalah media yang mempunyai unsur suara dan unsur gambar yang bisa dilihat, misalnya rekaman video, suara, dan sebagainya".

\section{Multimedia}

Multimedia, ditinjau dari bahasanya terdiri dari 2 kata yaitu multi dan media. Multi memiliki arti banyak atau lebih dari satu. Sedangkan media merupakan bentuk jamak dari medium, juga diartikan sebagai saran, wadah atau alat. Istilah multimedia diartikan sebagai transmisi data dan manipulasi semua bentuk informasi, baik berbentuk kata-kata, gambar, video, musik, angka, atau tulisan tangan dimana dalam dunia komputer, bentuk informasi tersebut diolah dari dan dalam bentuk data digital.

Secara umum media memiliki kegunaan yaitu memperjelas pesan agar tidak terlalu verbalistis, mengatasi keterbatasan ruang, waktu, tenaga dan daya indra, menimbulkan gairah belajar, interaksi lebih langsung antara murid dengan sumber belajar, memungkinkan anak belajar mandiri sesuai dengan bakat dan kemampuan visual, auditori dan kinestetiknya, memberikan rangsangan yang sama, mempersamakan pengalaman dan menimbulkan persepsi yang sama. Dengan demikian anak-anak lebih mudah mencerna bahan daripada tanpa bantuan media (sigit prasetyo, 2007).

\section{E. Adobe Photoshop CS3}

Adobe Photoshop CS3 digunakan untuk memodifikasi gambar atau foto secara profesional baik meliputi modifikasi obyek yang sederhana maupun yang rumit sekalipun. (Prihatna, Hengky, 2008).

Adobe Photoshop, atau biasa disebut Photoshop, adalah perangkat lunak editor citra buatan Adobe Systems yang dikhususkan untuk pengeditan foto/gambar dan pembuatan efek. (Komputer, Wahana, 2007).

\section{F. Macromedia Flash 8}

Macromedia flash 8 merupakan software yang dikeluarkan oleh perusahaan Macromedia Corp sebelum perusahaan Adobe resmi membelinya dan mengganti namanya menjadi Adobe Flash. Pada akhirnya setelah memperbaharui beberapa versi Adobe flash yang sudah ada, Adobe mengeluarkan flash versi terbaru yaitu Adobe Flash CC (Creative Clouds). Pada aplikasi Adobe Flash CC (Creative Clouds) terdapat beberapa perbedaan yang dapat ditemukan dari versi sebelumnya dan berbeda juga pada Macromedia Flash 8, baik pada tampilan, fitur-fitur yang mendukung dan terlihat lebih menarik (Dhani, 2003)

\section{G. Perancangan Desain}

Perancangan adalah membuat spesifikasi secara rinci mengenai arsitektur proyek, gaya dan kebutuhan material untuk proyek. Spesifikasi dibuat cukup rinci sehingga pada tahap berikutnya, yaitu material collecting dan assembly tidak diperlukan lagi keputusan baru, tetapi menggunakan apa yang sudah ditentukan pada tahap perencanaan. Autroring sistem bermanfaat pada saat perancangan dan dengan mudah menempatkan parameter kedalam sistem seperti yang telah ditentukan.Perancangan multimedia terdiri dari storyboard, struktur navigasi (Sutopo, 2003:33).

\section{METODOLOGI PENELITIAN}

Model air terjun (waterfall) biasa juga disebut siklus hidup perangkat lunak. Mengambil kegiatan dasar seperti spesifikasi, pengembangan, validasi, dan evolusi dan merepresentasikannya sebagai fase-fase proses yang berbeda seperti spesifikasi persyaratan, perancangan perangkat lunak, implementasi, pengujian dan seterusnya (Jogiyanto H.M, 2010).

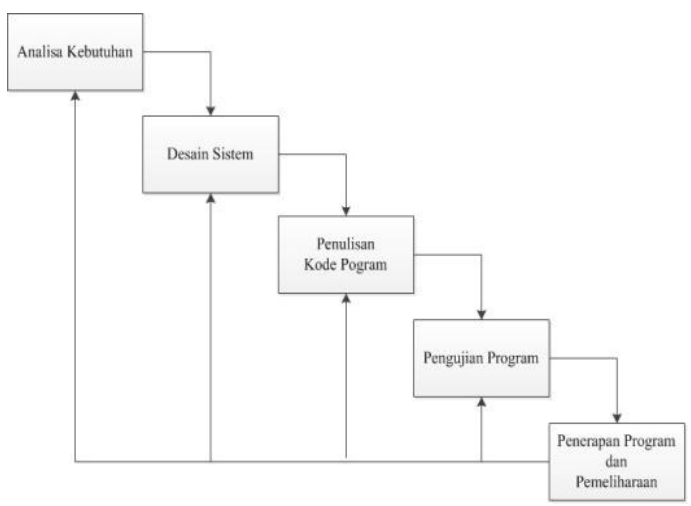

Gambar 1 Model Waterfall 
IN F ORMA T IK A

Jurnal Informatika, Manajemen dan Komputer, Vol. 11, No. 2, Desember 2019

eISSN : 2580-3042

pISSN : 1979-0694

Keterangan Menurut gambar diatas alur dari Model Waterfall sebagai berikut:

a) Analisa kebutuhan, proses pengumpulan kebutuhan dilakukan dengan datang dan wawancara langsung pada guru Tk Kartika 1.50 Kecamatan Sail Kota Pekanbaru untuk mespesifikasikan kebutuhan perangkat lunak agar dapat dipahami perangkat lunak seperti apa yang di butuhkan oleh siswa Tk Kartika 1.50 Desain sistem, pesain program yang akan dibuat juga akan selalu di konsultasikan dengan guru Tk Kartika 1.50 Kecamatan Sail Kota Pekanbaru agar menghasilkan desain yang menarik serta susuai keinginan dari Tk Kartika 1.50 Kecamatan Sail Kota Pekanbaru.

b) Penulisan kode, desain harus di translasilkan kedalam program perangkat lunak. Hasil dari tahap ini adalah program computer sesuai dengan desain yang telah di buat pada tahap desain.

c) Pengujuan program, pengujian aplikasi nantinya juga akan melibatkan guru Tk Kartika 1.50 Kecamatan Sail Kota Pekanbaru, untuk memastikan setiap fungsi dari setiap menu pada aplikasi berjalan dengan baik serta meminimalisasi kesalahan (error) pada aplikasi

d) Penerapan dan pemeliharaan, Software yang sudah jadi, dijalankan serta dilakukan pemeliharaan / Maintenance. Pemeliharaan termasuk dalam memperbaiki kesalahankesalahan yang tidak ditemukn pada langkah sebelumnya.

\section{HASIL DAN PEMBAHASAN}

Dalam tampilan menu utama terdapat dua tombol utama yaitu tombol menu pembuka untuk memulai ke menu utama pembelajaran bahasa inggris dasar. terdapat pada Gambar 5.5

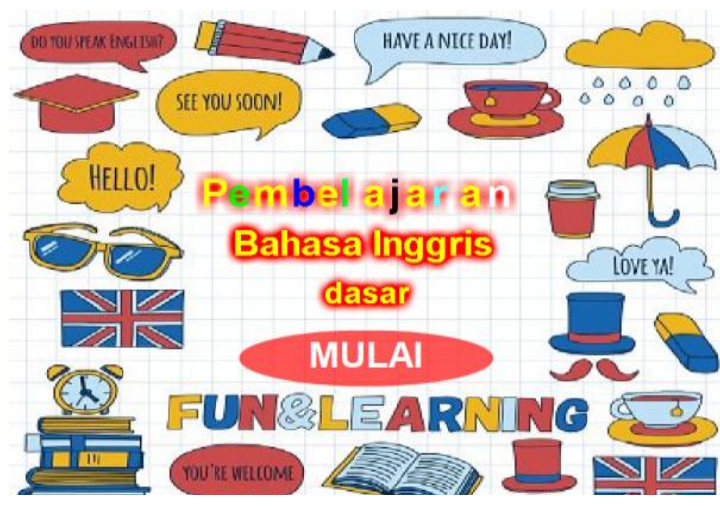

Gambar 2. Tampilan Pembuka

\section{Tampilan Menu Utama}

Dalam tampilan menu utama terdapat tiga pilihan menu yaitu materi bahasa inggris yang berisi empat menu materi yaitu menu sayuran, menu anggota tubuh, menu hewan, benda dan warna. dan game. Menu utama hanya terdapat tombol exit untuk kembali ke menu pembuka. Tampilan menu utama dapat dilihat pada Gambar 5.6 dibawah ini :

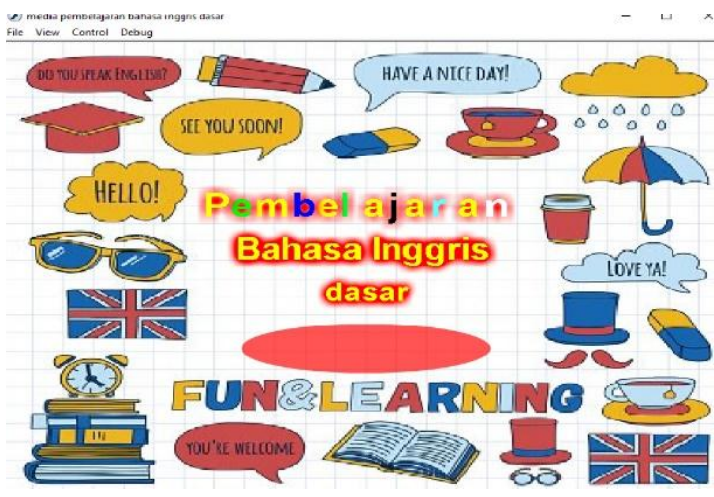

Gambar 3. Tampilan Menu Utama

\section{Tampilan Halaman Materi}

Pada menu materi bahasa inggris terdapat lima menu yaitu menu sayuran yang terdiri dari sayuran, menu anggota tubuh yang terdiri dari bagian dari tubuh, menu hewan yang terdiri dari nama-nama hewan, menu warna yang terdiri dari warna-warna, dan menu benda yang terdiri dari benda. Didalam menu ini juga terdapat tombol kembali kemenu utama tampilan menu dapat dilihat pada Gambar 4 dibawah ini:

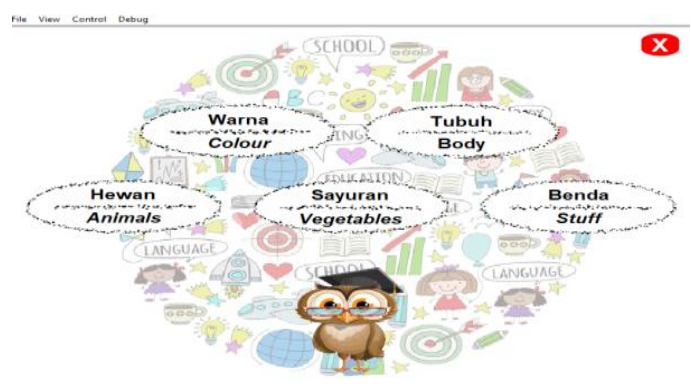

Gambar 4. Tampilan Halaman Pelajaran

\section{Tampilan Halaman Sayuran}

Pada halaman sayuran akan membahas mengenai nama-nama sayuran. Pada halaman sayuran ini dilengkapi dengan audio agar lebih mudah dalam memahami materi nama sayuran dalam bahasa inggris. Pada halaman sayuran ini juga terdapat tombol keluar yang berfungsi untuk 
IN F ORMA T I K A

Jurnal Informatika, Manajemen dan Komputer, Vol. 11, No. 2, Desember 2019

eISSN : 2580-3042

pISSN : 1979-0694

kembali ke menu materi. Tampilan menu dapat dilihat pada Gambar 5 dibawah ini:

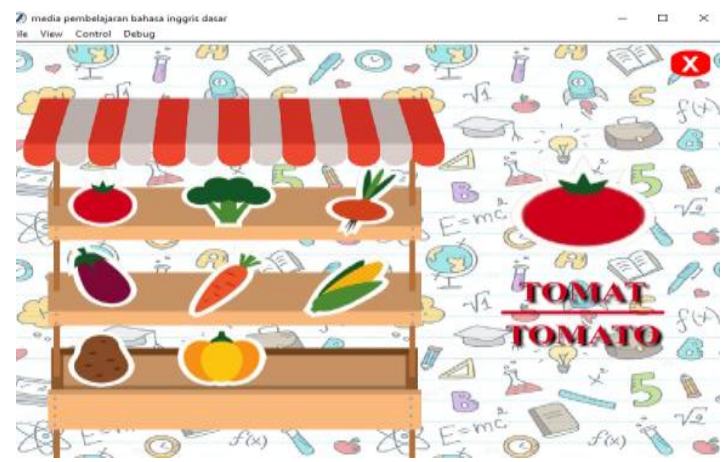

Gambar 5. Tampilan Halaman Sayuran

\section{Tampilan Halaman Anggota Tubuh}

Pada halaman anggota tubuh akan membahas mengenai dari anggota tubuh. Pada halaman anggota tubuh ini dilengkapi dengan audio agar lebih mudah dalam memahami materi nama anggota tubuh dalam bahasa inggris. Pada halaman anggota tubuh ini juga terdapat tombol keluar yang berfungsi untuk kembali ke menu materi. Tampilan menu dapat dilihat pada Gambar 6 dibawah ini:

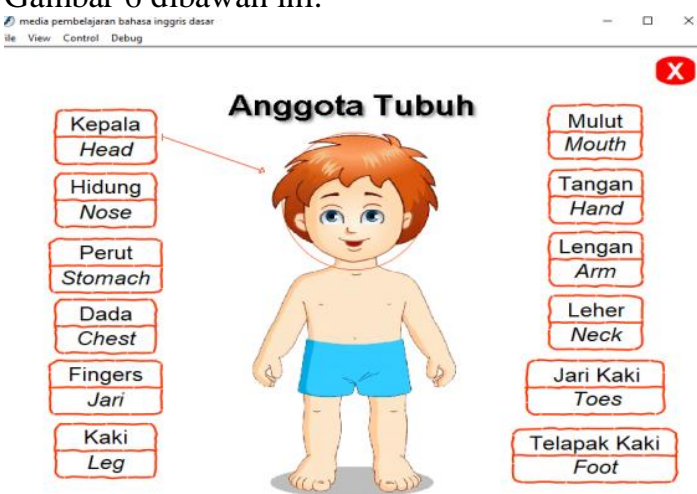

Gambar 6. Tampilan Halaman Anggota Tubuh

\section{Tampilan Halaman Hewan}

Pada halaman hewan akan membahas mengenai nama-nama hewan. Pada halaman hewan ini dilengkapi dengan audio agar lebih mudah dalam memahami materi nama hewan dalam bahasa inggris. Pada halaman hewan ini juga terdapat tombol keluar yang berfungsi untuk kembali ke menu materi. Tampilan menu dapat dilihat pada Gambar 7 dibawah ini:

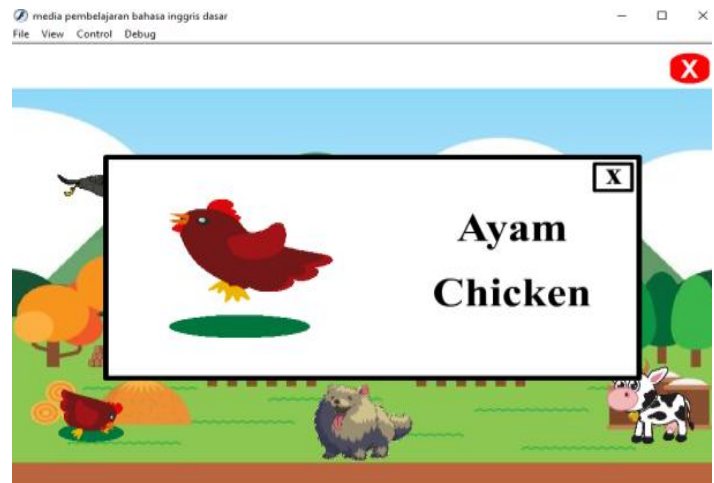

Gambar 7. Tampilan Halaman Hewan

\section{Tampilan Halaman Warna}

Pada halaman Warna akan membahas mengenai nama-nama warna. Pada halaman warna ini dilengkapi dengan audio agar lebih mudah dalam memahami materi nama warna dalam bahasa inggris. Pada halaman warna ini juga terdapat tombol keluar yang berfungsi untuk kembali ke menu materi. Tampilan menu dapat dilihat pada Gambar 8 dibawah ini:

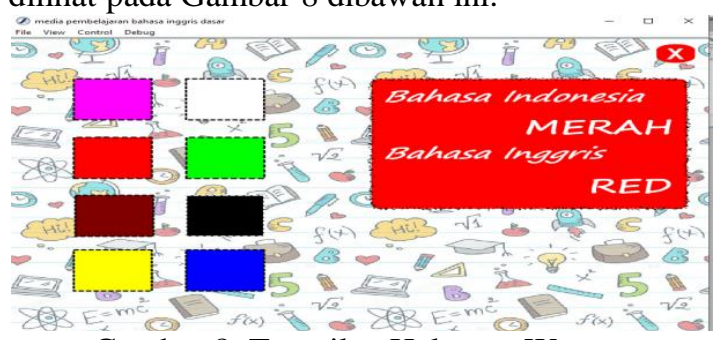

Gambar 8. Tampilan Halaman Warna

\section{Tampilan Halaman Benda}

Pada halaman benda akan membahas mengenai nama-nama warna. Pada halaman benda ini dilengkapi dengan audio agar lebih mudah dalam memahami materi nama benda dalam bahasa inggris. Pada halaman benda ini juga terdapat tombol keluar yang berfungsi untuk kembali ke menu materi. Tampilan menu dapat dilihat pada Gambar 9 dibawah ini:

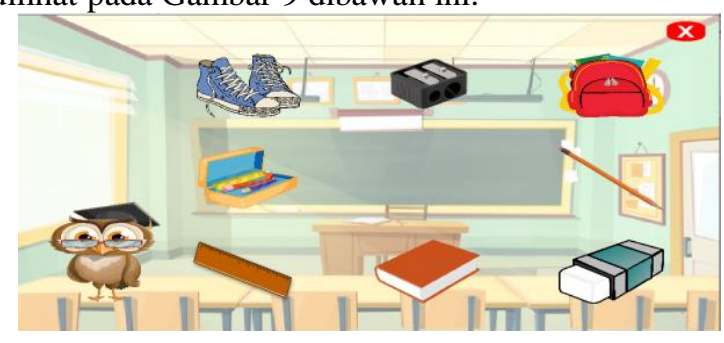

Gambar 9. Tampilan Halaman Benda

\section{Tampilan Halaman Game}

Pada menu game terdapat dua menu game yaitu fuzzel dan voice untuk menampilan game 
IN F O R M A I I A

Jurnal Informatika, Manajemen dan Komputer, Vol. 11, No. 2, Desember 2019

eISSN : 2580-3042

pISSN : 1979-0694

didalam menu ini juga terdapat tombol kembali kemenu utama tampilan menu dapat dilihat.

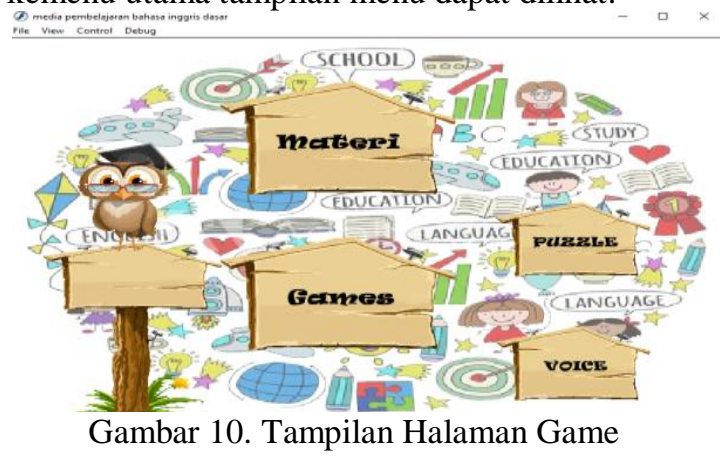

\section{Tampilan Halaman Fuzzel}

Pada halaman fuzzell terdapat game menyusun gambar dan terdapat juga tombol kembali kemenu utama dapat dilihat pada Gambar 11 dibawah ini:

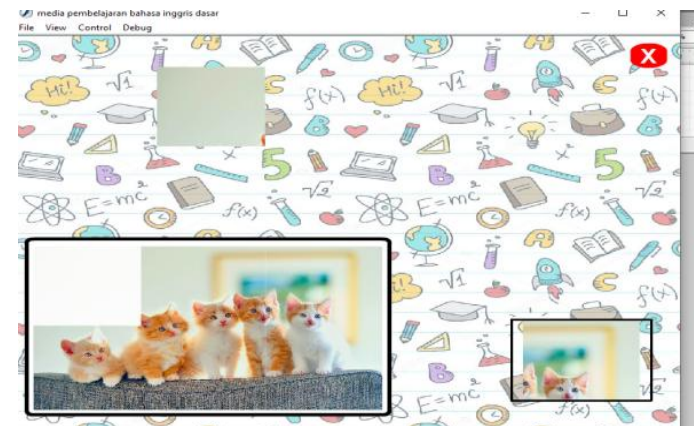

Gambar 11. Tampilan Halaman fuzzel

\section{Tampilan Halaman Voice}

Pada halaman voice terdapat game menebak suara hewan dan terdapat juga tombol kembali kemenu utama dapat dilihat pada gambar 11 dibawah ini:

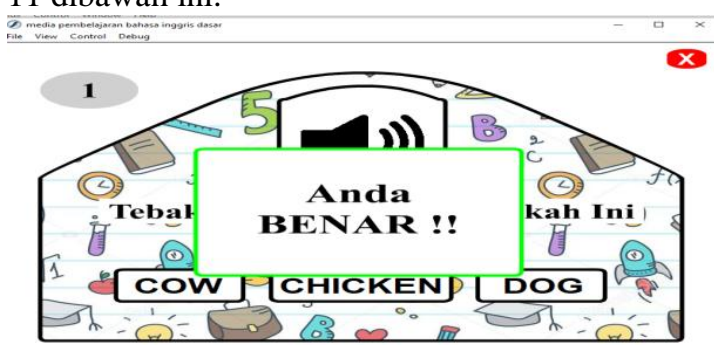

Gambar 12. Tampilan Halaman Voice

\section{KESIMPULAN}

Berdasarkan hasil penelitian pembuatan aplikasi multimedia pembelajaran bahasa inggris dasar dengan menggunakan macromedia flash 8 di TK Kartika 1.50 kecamatan Sail kota Pekanbaru ini dapat diambil kesimpulan yaitu Aplikasi multimedia pembelajaran bahasa inggris dasar ini menggunakan macromedia flash 8 dibuat dengan beberapa animasi, audio, dan video dimana pengguna juga dapat berinteraksi dengan beberapa fitur yang telah disediakan dan terdapat beberapa pertanyaan yang digunakan untuk menguji kemampuan daya ingat dalam hal pemahaman tentang bahasa inggris dasar sejak dini terutama pada anak-anak TK Kartika 1.50 Sail Pekanbaru. Aplikasi multimedia pembelajaran bahasa inggris dengan menggunakan macromedia flash 8 ini dapat diburning ke dalam CD (Compact Disk) sehingga memudahkan pengguna dalam menyampaikan dan mempelajari materi bahasa inggris dasar dengan menggunakan alat teknologi yang ada dimana saja dan kapan saja. Saran untuk penelitian kedepannya adalah dengan penerapa Sistem Pendukung Keputusan untuk menilkai prestasi belajar siswa seperti penelitian terdahulu oleh yuda irawan (2017) dengan judul Sistem Pendukung Keputusan untuk Penilaian Prestasi Belajar Siswa pada Sekolah Dasar Negeri 167 Pekanbaru, hasil penelitian ini adalah sistem pendukung keputusan yang mampu memberikan rekomendasi tentang siswa berprestasi yang merupakan hasil dari pengolahan multikriteria dengan menggunakan metode Analytic Hierarchy Process (AHP).

\section{REFERENSI}

Abdul Kadir. 2003. Pengenalan Sistem Informasi. Yogyakarta :Andi

A.S Rosa, Shalahuddin. M.2018. Rekayasa Perangkat Lunak Terstruktur Berorientasi Objek. Bandung: Informatika.

Dhani,Y.2003.Panduan Lengkap Macromedia Flash MX. AndiOffset:Yogyakarta

Hakim,Lukmanul dan Mutmainah, Siti.2003.Teknik Jitu Menguasai Flash MX.

Irawan, Y. (2019). Sistem Informasi Pemasaran Busana Syar'i Dengan Penerapan Customer Relationship Management (CRM) Berbasis Web. INTECOMS: Journal of Information Technology and Computer Science, 2(1), 19.

PT.Elek Media Komputindo:Jakarta.

Y. Irawan, U. Rahmalisa, R. Wahyuni, and Y. Devis, "Sistem Informasi Penjualan Furniture pada CV . Satria Hendra Jaya Pekanbaru Berbasis Web ( Sales Information Systems Furniture in CV . Satria Hendra Jaya Pekanbaru Based on 
INFORM T I K A

Jurnal Informatika, Manajemen dan Komputer, Vol. 11, No. 2, Desember 2019

eISSN : 2580-3042

pISSN : 1979-0694

Web )," J. Teknol. Inf. dan Multimed., vol. 1, no. 2, pp. 150-159, 2019.

Shalahuddin, M dan S, Rosa A. 2013.Rekayasa Perangkat Lunak Terstruktur dan Berorientasi Objek. Informatika. Bandung

Sutopo, Ariesto Hadi.2003. Multimedia Interaktif dengan Flash. Graha Ilmu. Yogyakarta.

Mukhtar, H. (2018). Sistem Informasi Deteksi Kehadiran dan Media Penyampaian Pengumuman Dosen dengan Menggunakan Teknik Pengenalan Qr Code. RABIT (Jurnal Teknologi dan Sistem Informasi Univrab), 3(2), 89-99.

Irawan, Y. (2019). Sistem Informasi Pemasaran Busana Syar'i Dengan Penerapan Customer Relationship Management (CRM) Berbasis Web. INTECOMS: Journal of Information Technology and Computer Science, 2 (1), 19. 